\title{
Malformação Linfática Microcística Simulando Condilomas Acuminados
}

\section{Microcystic Lymphatic Malformation Mimicking Condylomata Acuminata}

\author{
Diogo TEIXEIRA $\rrbracket^{1}$, Eduarda OSÓRIO FERREIRA ${ }^{1}$, Artur CÉSAR ${ }^{1}$ \\ Acta Med Port 2022 Jan;35(1):68-69 - https://doi.org/10.20344/amp.14022
}

Palavras-chave: Adulto; Anomalias Linfáticas; Condilomas Acuminados; Escroto; Linfedema; Malformação Linfática Microcística; Pénis

Keywords: Adult; Condylomata Acuminata; Lymphatic Abnormalities; Lymphedema; Scrotum

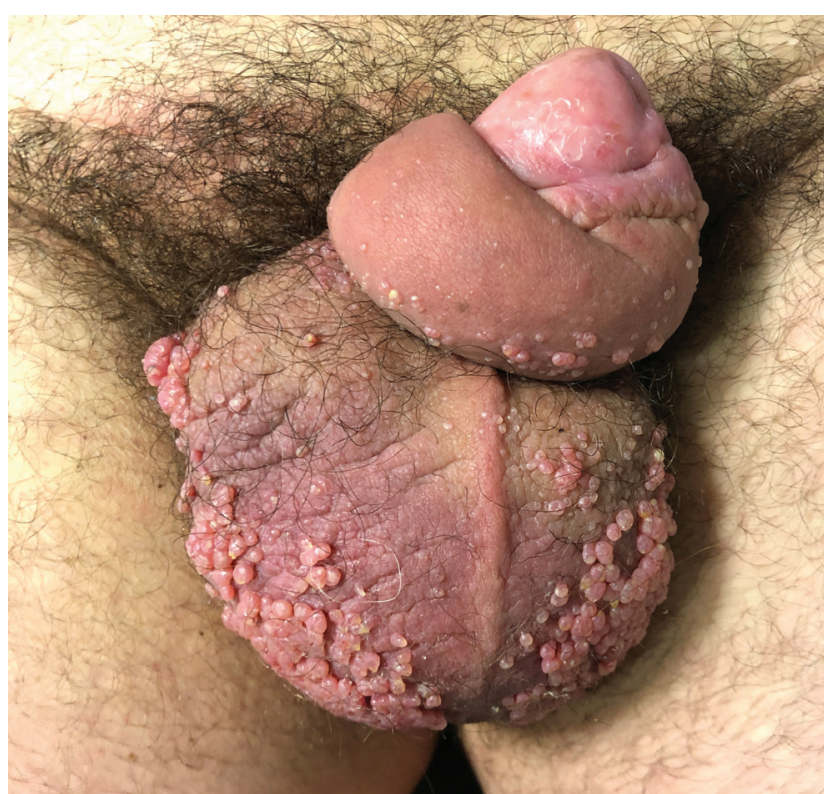

Figura 1 - Linfedema crónico marcado do pénis e do escroto, com múltiplas pápulas milimétricas, algumas agrupadas em placas de aspeto verrucoso, algumas cor de pele, outras translúcidas

Doente do sexo masculino de 49 anos, foi referenciado ao Serviço de Dermatologia por lesões no pénis e escroto, assintomáticas, de crescimento lento e com um ano de evolução, previamente diagnosticadas como condilomas. Apresentava também linfedema crónico da região genital, consequência do tratamento de um carcinoma do pénis submetido a circuncisão e linfadenectomia inguinal há 18 anos. Ao exame objetivo, observaram-se múltiplas pápulas agrupadas, algumas cor de pele, outras translúcidas, no escroto e pénis (Fig.s 1, 2). O diagnóstico clínico de malformação linfática microcística foi confirmado após a biópsia revelar ligeira acantose epidérmica e dilatação linfática marcada, com infiltrado polimórfico ligeiro a moderado, edema e fibrose. Uma vez que o diagnóstico de condilomas foi descartado, não foram rastreadas outras infeções sexualmente transmissíveis.

A malformação linfática microcística é uma malforma-

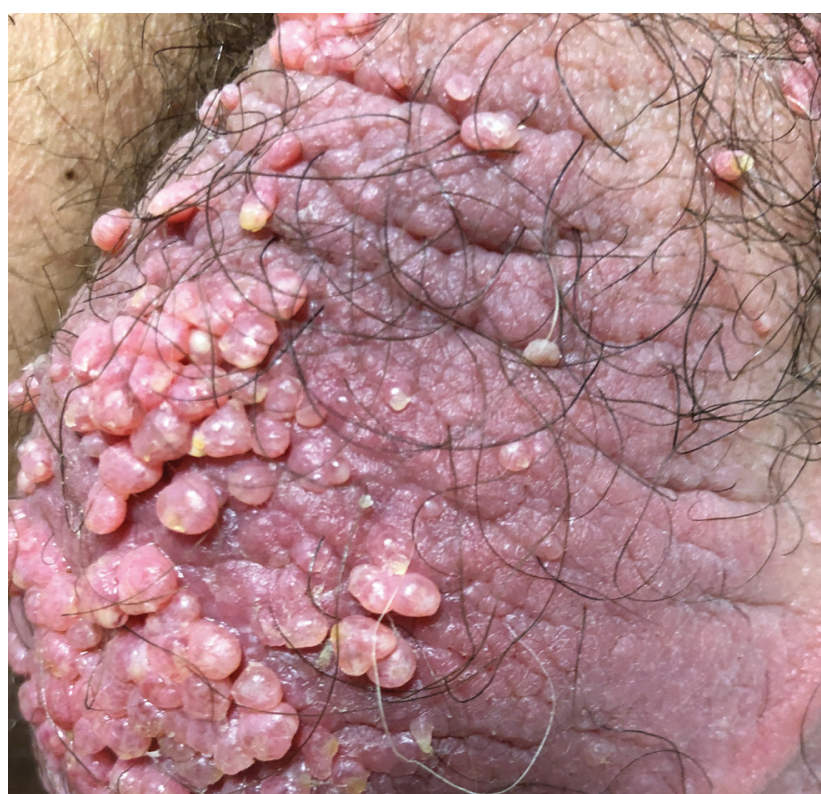

Figura 2 - Pormenor das lesões no escroto

ção vascular. Pode ser congénita ou adquirida (nomeadamente secundária a linfedema), sendo raro o aparecimento em adultos..$^{1,2} \mathrm{Na}$ região genital, as lesões podem ter um aspeto verrucoso, levando ao diagnóstico errado de condilomas. ${ }^{1} \mathrm{O}$ tratamento destas lesões é a excisão cirúrgica, sendo a recorrência frequente. ${ }^{3,4}$ Neste caso, dada a localização e associação ao linfedema, optou-se pela atitude conservadora.

\section{CONTRIBUTO DOS AUTORES}

DT, EOF, AC: Todos os autores tiveram igual contributo na redação e revisão final do manuscrito.

\section{PROTECÇÃO DE PESSOAS E ANIMAIS}

Os autores declaram que os procedimentos seguidos estavam de acordo com os regulamentos estabelecidos pelos responsáveis da Comissão de Investigação Clínica

1. Serviço de Dermatovenereologia. Centro Hospitalar Vila Nova de Gaia/Espinho. Vila Nova de Gaia. Portugal.

$\triangle$ Autor correspondente: Diogo Teixeira. diogomsantosteixeira@gmail.com

Recebido: 30 de abril de 2020 - Aceite: 09 de junho de 2020 - First published: 27 de setembro de 2021 - Online issue published: 03 de janeiro de 2022 Copyright $\odot$ Ordem dos Médicos 2021 
e Ética e de acordo com a Declaração de Helsínquia da Associação Médica Mundial.

\section{CONFIDENCIALIDADE DOS DADOS}

Os autores declaram ter seguido os protocolos do seu centro de trabalho acerca da publicação de dados.

\section{CONSENTIMENTO INFORMADO}

Obtido.

\section{REFERÊNCIAS}

1. Wang S, Krulig E, Hernandez C. Acquired microcystic lymphatic malformation of the distal upper extremity mimicking verrucae vulgaris. Pediatr Dermatol. 2013;30:e78-82.

2. Paolino G, Rizzo N, Mercuri SR. Dermoscopy and pathological correlation of microcystic cutaneous lymphatic malformation: a rare

\section{CONFLITOS DE INTERESSE}

Os autores declaram não ter qualquer conflito de interesse relativamente ao presente artigo.

\section{FONTES DE FINANCIAMENTO}

Sem fontes externas de financiamento para a realização deste artigo.

cutaneous entity. Int J Dermatol. 2020;59:e122-4.

3. Elluru RG, Balakrishnan K, Padua HM. Lymphatic malformations: diagnosis and management. Semin Pediatr Surg. 2014;23:178-85.

4. Vignes $S$, Arrault M, Trévidic P. Surgical resection of vulva lymphoedema circumscriptum. J Plast Reconstr Aesthet Surg. 2010;63:1883-5. 